\title{
Variation of Geospatial Representation of Community Hazard Maps with Disaster Prevention Activities
}

\author{
Toru Murayama ${ }^{\text {a }}$ \\ ${ }^{a}$ Nagoya University of Economics, tmurayama@nagoya-ku.ac.jp
}

Keywords: Mapping disaster risk, Evacuation route, Disaster resilience, Local community

\begin{abstract}
:
After the Great Hanshin-Awaji Earthquake, the limitation of assistance by public bodies in the time of such massive natural disaster struck has been recognized. Moreover, it has acknowledged that self-help by suffered families and mutual support of neighbours are crucial to mitigate further damage. Since then, the major focus of the disaster management in Japan has altered to effectiveness of non-structural measures for a forecast crisis. Thus, improving the existing hazard maps into those that show actions to be taken by residents in an easy-to-understand manner has been dictated by the national government.
\end{abstract}

This study discusses the geospatial representation of an alternative hazard map from residents' perspective with the local community activities. Those mapping activities have been conducted for some years in a study area. Then, the geospatial information represented on the community hazard map has gradually changed. At the early year of the activities, the map represents the certainty of disaster risks. At the late year of those after few modifications have made, the map mainly argues the possibility of risks from residents' perspective.

A research area of this study is Toyohashi-city, Aichi prefecture. The city is populated roughly 380,000 people, is located about $84 \mathrm{~km}$ east of Nagoya-city which is the economic center of the prefecture. And also, it is in the area along the Nankai Trough. Therefore, if the Nankai Trough Earthquake occurs, the maximum seismic intensity around Toyohashi-city is estimated more than upper 6. The crisis-management division of the city estimates more than 8,000 dwellings and 400 casualties suffered from the massive earthquake. The capability of assistance by public bodies alone isn't enough to mitigate damage of such disaster; therefore, the improvement of disaster reduction capability of communities is critical for the disaster management of Toyohashi-city. There are 52 school-districts in Toyohashi. And, it is expected that those school-districts will be the main constituent of the disaster prevention activity when the Nankai Trough Earthquake strikes. The community hazard map in the city is the result of the local activities at those schooldistricts.

Figure 1 is an alternative hazard map in Toyohashi, called "Community Map for Disaster Preservation" which is the outcome of local activities at MIYUKI school-district. The community map for disaster preservation has been implemented since the year of 2013. 10 out of 52 school-districts of the city have already made own community hazard maps with local disaster prevention activities. The community hazard map of the MIYUKI was made in 2015, illustrates the location of possible flooding at a street drain and risk of house collapse or fallen objects during an earthquake. Those kinds of information are gathered through the series of field works of school education or social education. And, the map describes those risks along with a recommended evacuation route for residents.

Figure 2 is a summary of the variation of geospatial representation among the community hazard maps of Toyohashicity. The community hazard maps made in the year of 2013 tend to argue the safety of a school student's evacuation. The maps illustrate the intersection of a school route with a hazardous area such as a junction, a bridge or a railroad crossing. And also, it represents the vicinity of spots where children get supports such as a police office or a children's refuge house. On the other hand, the community hazard maps made in 2015 tend to represent the intersection or vicinity of a route with the location of possible risks observed through the local community activities. The evacuation route on the maps is the direction from a temporary evacuation neighbourhood to a designated evacuation site. The community hazard map in the late year argues the evacuation of not only students also entire residents in the manner of easy-tounderstand for them.

In conclusion, the community map for disaster preservation in Toyohashi-city during 2013-2015 has made progress in the geospatial representation. Such variation of the representation is able to summarize that the map becomes to describe uncertainties of disaster risks observed by local residents. Mapping usually requires the accuracy of information conducted by a specialist. However, the community hazard map needs to illustrate the uncertainties on them. Especially, people who don't have enough knowledge of mapping plot the location of the possible risks by natural disaster. Thus, the standardized method of plotting the uncertainties on a map is indispensable for the future of a hazard map with self-help and mutual support. 


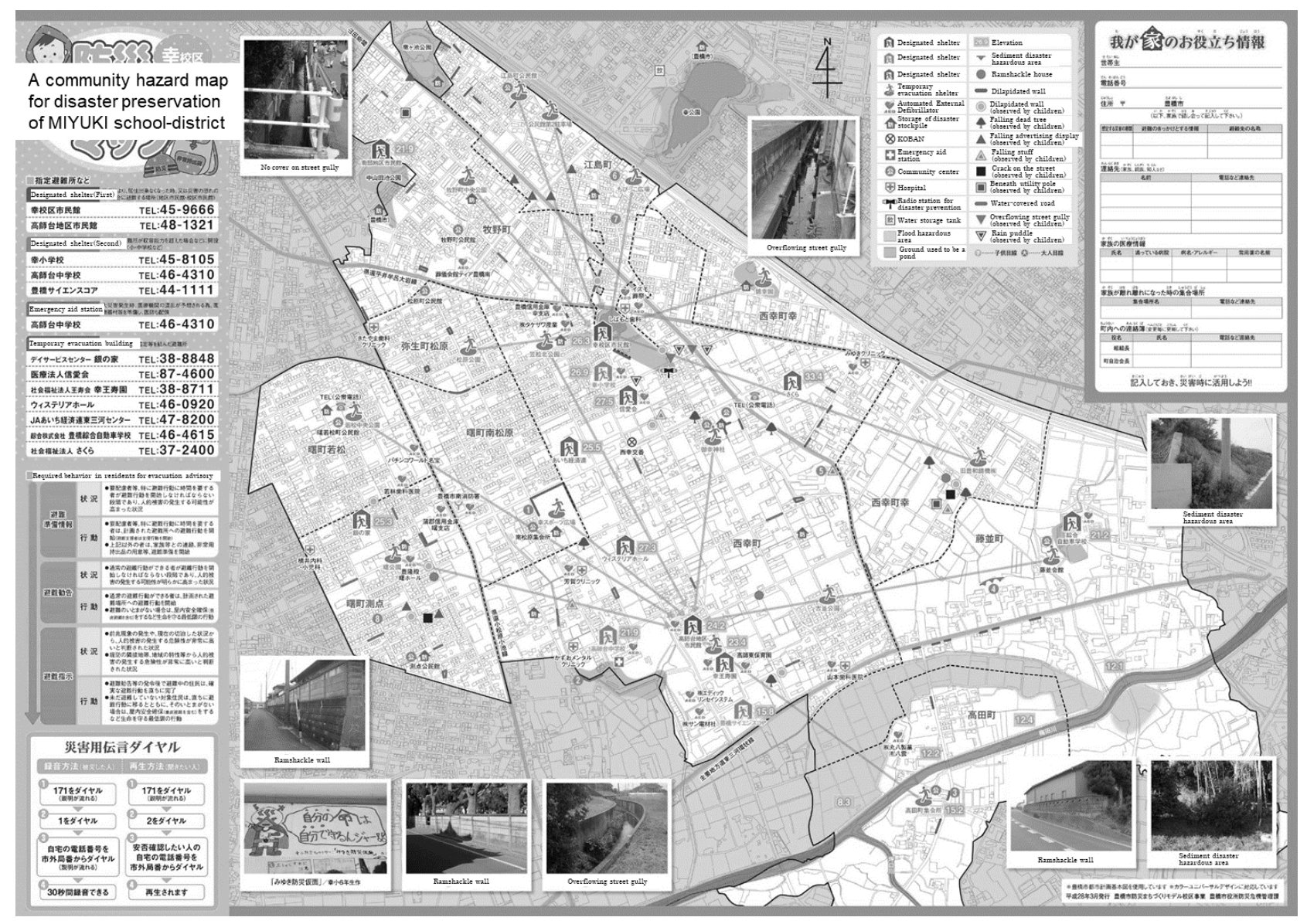

Figure 1. A community hazard map for disaster preservation of MIYUKI school-district

\section{[Early Stage]}

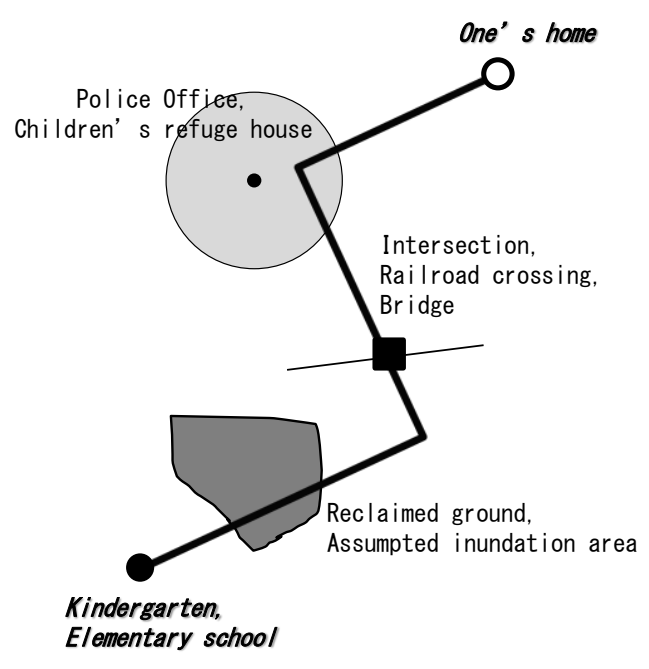

[Later Stage]

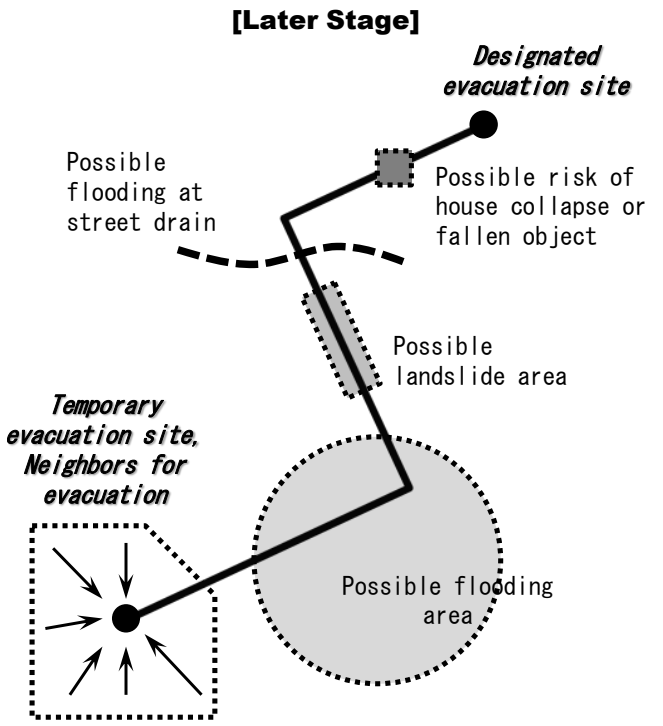

Figure 2. Variation of geospatial representation of the community hazard map of Toyohashi-city 